\title{
Recombinant human thyroid stimulating hormone in 2008: focus on thyroid cancer management
}

\author{
Ann Gramza' \\ Kathryn G Schuff ${ }^{2}$ \\ 'Division of Medical Oncology, \\ Oregon Health and Science University, \\ Portland, OR USA; ${ }^{2}$ Division of \\ Endocrinology, Oregon Health and \\ Science University, Portland, OR USA
}

\begin{abstract}
Radioiodine (RAI) ablation following thyroidectomy is standard of care treatment for patients with intermediate or high risk differentiated thyroid cancer. Traditionally, this has been achieved by forgoing thyroid hormone replacement postoperatively, allowing endogenous thyroid stimulating hormone (TSH) levels to rise. This rise in TSH provides the stimulus for RAI uptake by the thyroid remnant, but is associated with clinical hypothyroidism and its associated morbidities. Recombinant human TSH (rhTSH, thyrotropin alfa [Thyrogen ${ }^{\circledR}$ ], Genzyme Corporation, Cambridge, MA, USA) was developed to provide TSH stimulation without withdrawal of thyroid hormone and clinical hypothyroidism. Phase III studies reported equivalent detection of recurrent or residual disease when rhTSH was used compared with thyroid hormone withdrawal (THW). These trials led to its approval as an adjunctive diagnostic tool for serum thyroglobulin ( $\mathrm{Tg}$ ) testing with or without RAI imaging in the surveillance of patients with differentiated thyroid cancer. Recently, rhTSH was given an indication for adjunctive preparation for thyroid remnant ablation after phase III studies demonstrated comparable outcomes for rhTSH preparation when compared with THW. Importantly, rhTSH stimulation has been found to be safe, well tolerated, and to result in improved quality of life. Here, we review the efficacy and tolerability studies leading to the approval for the use of rhTSH in well-differentiated thyroid cancer management.
\end{abstract}

Keywords: recombinant human thyroid stimulating hormone, thyroid cancer, radioiodine, ablation, Thyrogen ${ }^{\circledR}$, thyrotropin alfa

\section{Introduction}

The use of exogenous thyroid stimulating hormone (TSH) in the evaluation and management of thyroid cancer dates back over 50 years with the use of bovine TSH to stimulate iodine uptake for radioiodine (RAI) diagnostic studies and therapy. Although use of bovine TSH was eventually abandoned because of allergic reactions, the development of recombinant human TSH (rhTSH, thyrotropin alfa [Thyrogen ${ }^{\circledR}$ ], Genzyme Corporation, Cambridge, MA, USA) has dramatically changed the paradigm for the management and follow-up of patients with thyroid cancer. This review will introduce issues in the management of patients with thyroid cancer, and review the pharmacology, mode of action, and method of administration of rhTSH. We will briefly review studies of the efficacy of rhTSH in diagnostic evaluation of thyroid cancer, and then focus the bulk of the review on studies of the efficacy of rhTSH-stimulated RAI therapy for thyroid remnant ablation and treatment of metastases. Finally, we review the safety, tolerability and impact on patients' quality of life of rhTSH preparation compared with thyroid hormone withdrawal (THW).

\section{Management issues in thyroid cancer and use of radioiodine}

Radioiodine is an important component of differentiated thyroid cancer treatment and surveillance. It has three main roles: 1) Ablation of residual normal thyroid tissue, 
2) Diagnostic scanning to detect residual/recurrent disease and 3 ) Treatment of residual/recurrent disease. Radioiodine administration following thyroidectomy ("remnant ablation") is performed to reduce the risk of thyroid cancer recurrence and improve the accuracy of surveillance strategies. The two goals of treatment are to destroy micrometastatic or residual disease, and ablate remaining normal thyroid tissue to facilitate RAI scanning and use of Tg as a tumor marker. No prospective studies have been done to address the question of which patients benefit from this treatment strategy. However, based on large retrospective series, the published consensus guidelines from both the European Thyroid Association (ETA) and American Thyroid Association (ATA) recommend RAI ablation for patients with higher stage disease and recommend considering ablation in lower risk patients with tumors larger than 1 or $1.5 \mathrm{~cm}$ (Cooper et al 2006; Pacini et al 2006b).

The use of RAI for all three purposes relies on the ability of both normal and malignant thyroid tissue to transport iodine for synthesis of thyroglobulin, triiodothyronine and thyroxine in response to TSH. An overview of the procedures for thyroid remnant ablation and diagnostic scanning are shown in Figure 1 and 2, respectively. TSH stimulation historically has been achieved by discontinuation of thyroid hormone replacement for 5 to 6 weeks, (thyroid hormone withdrawal, THW), allowing endogenous TSH levels to rise (Figure 1a and 1b). The optimal TSH level for ablation is felt to be $>30 \mathrm{mU} / \mathrm{L}$, based on a study that demonstrated that low TSH levels were more likely to be associated with low iodine uptake, which was more robust on reevaluation with a higher TSH (Edmonds et al 1977). In addition to high TSH levels, iodine depletion, such as with a low iodine diet for 1 to 2 weeks, is important for optimal RAI uptake. If desired to assist in treatment decisions, diagnostic RAI whole body scans (WBS) are performed with a tracer dose of 74 to 185 $\mathrm{MBq}(2-5 \mathrm{mCi}){ }^{131} \mathrm{I}$ and the diagnostic scan obtained 48 to 72 hours later as shown in Figure 1b. Radioiodine at a dose of 1.1 to $3.7 \mathrm{GBq}(30-100 \mathrm{mCi})$ is administered for remnant ablation, with higher doses if residual disease is known or suspected or the tumor has unfavorable histology or if treatment of metastatic disease is planned. The patient is placed back on levothyroxine suppressive therapy, as appropriate, and approximately 1 week after the treatment dose of RAI, a post-therapy WBS is performed to better assess for residual or metastatic disease. Substitution of rhTSH stimulation for TSH stimulation by THW for diagnostic evaluations (shown in Figure 2b and reviewed by Cooper et al (2006) or for thyroid remnant ablation (shown in Figures $1 \mathrm{c}$ and $1 \mathrm{~d}$ ), has been published by a number of centers, allowing patients to remain on levothyroxine therapy and avoid the symptoms of hypothyroidism (Robbins et al 2001; Pacini et al 2002; Robbins et al 2002b; Barbaro et al 2003; Barbaro et al 2006; Pacini et al 2006a; Pilli et al 2007; Rosario et al 2008; Taieb et al 2008; Tuttle et al 2008). Over the last 3 years, thyrotropin alfa (Thyrogen ${ }^{\circledR}$ ) has been approved for RAI ablation by the United States Food and Drug Administration (FDA, 2007), in Europe (2005), and in certain Asian (2007) and South American countries (2006). Further discussion of the efficacy of rhTSH-stimulated remnant ablation follows in a subsequent section. Pertinent issues include the utility and logistics of the diagnostic preablation scan, selection of the RAI therapy dose, and the extent of iodine depletion regimens.

Traditionally, follow-up surveillance RAI WBS and stimulated thyroglobulin (Tg) measurements (Figure 2) are performed every 12 months after remnant ablation for several years and then periodically. If distant metastases are discovered during follow-up, patients may be incurable but can be retreated with various modalities (surgery, RAI) to reduce the tumor burden and provide a possible survival benefit.

\section{Thyrotropin pharmacology and mode of action}

Thyrotropin alfa is a synthetic recombinant human thyroid stimulating hormone (rhTSH) produced in Chinese hamster ovary cells. Although they have the same amino acid sequence, rhTSH differs from TSH synthesized endogenously by the human pituitary gland, in that rhTSH is sialylated but not sulfated, whereas endogenous TSH is a mixture of both glycosylation forms. Like the endogenous form, rhTSH binds to TSH receptors on normal thyroid follicular cells or well-differentiated thyroid cancer cells. RhTSH acts via the TSH receptor, a seven transmembrance G-protein coupled receptor, to activate the adenylate cyclase and phosphatidylinositol signaling pathways. TSH induces thyroid growth and thyroid hormone synthesis and secretion (Dumont et al 1992). It stimulates many of the steps of thyroid hormone synthesis including uptake of iodide into the thyroid follicular cell and subsequent organification of iodine at the thyroid follicular lumen. TSH also stimulates Tg gene expression and thyroid hormone secretion, involving pinocytosis of stored $\mathrm{Tg}$ into the thyroid follicular cell and limited lysosomal proteolysis to release T4, T3 and Tg. Because of the differences in glycosylation, rhTSH has a lower affinity for and bioactivity at the TSH receptor (Szkudlinski et al 1993), but also a significantly longer elimination half-life. 


\section{A. Thyroid hormone withdrawal ablation}

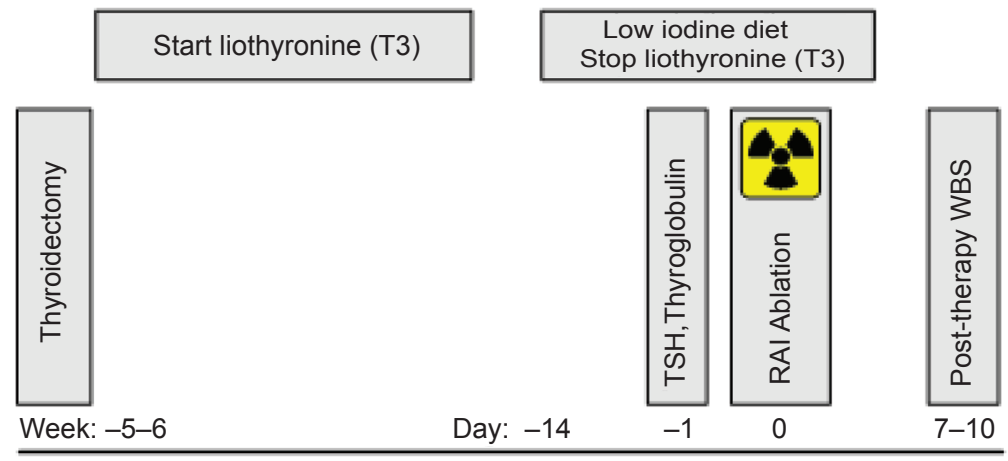

B. Thyroid hormone withdrawal ablation with diagonostic scan

\section{Start liothyronine (T3)}

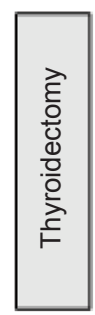
Stop liothyronine (T3)

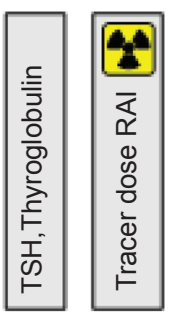

$-1$

0

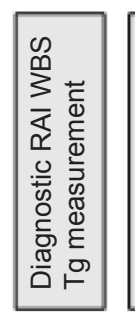

2-3

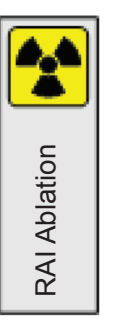

4-5

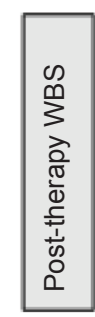

$11-14$

\section{C. rhTSH-stimulated ablation}
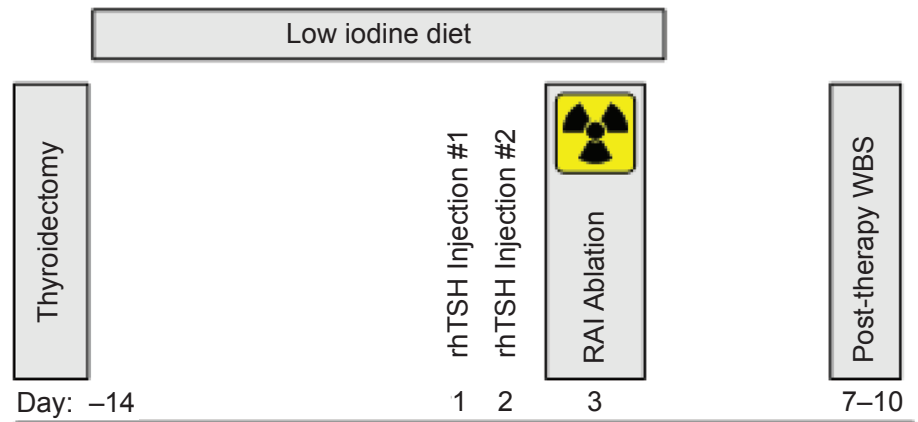

Day: -14

12

3

D. rhTSH-stimulated ablation with preceding diagonostic scan

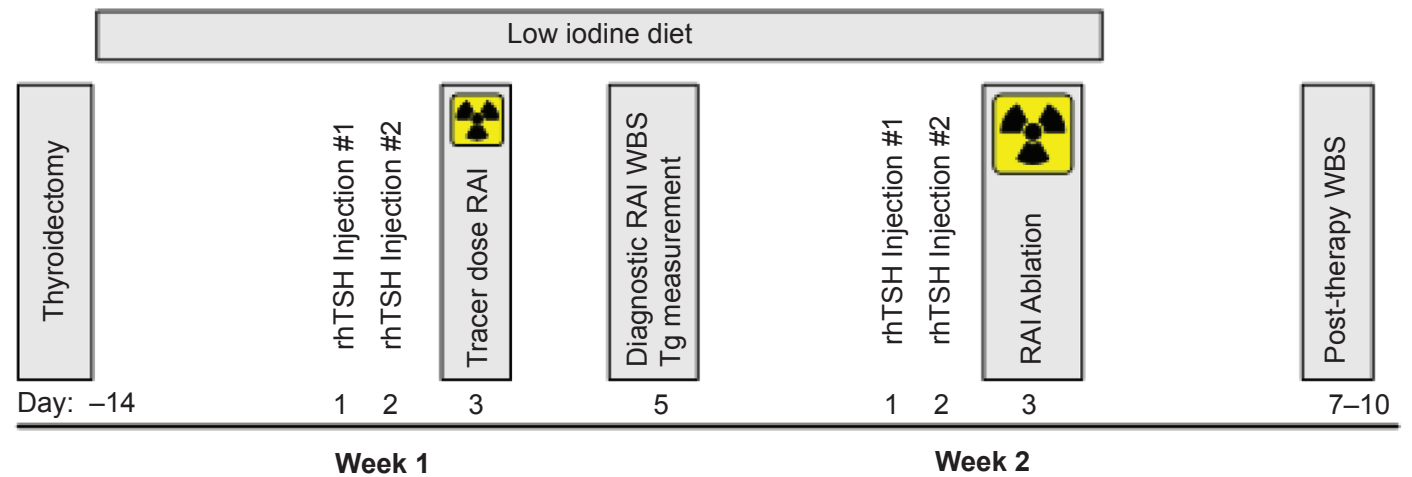

Figure I Schedules for radioiodine ablation.

Abbreviations: T3, liothyronine; TSH, thyroid stimulating hormone; RAI, radioiodine;WBS, whole body scan; Tg thyroglobulin; rhTSH, recombinant human thyroid stimulating hormone. 


\section{A. Thyroid Hormone Withdrawal diagnostic WBS and Tg}

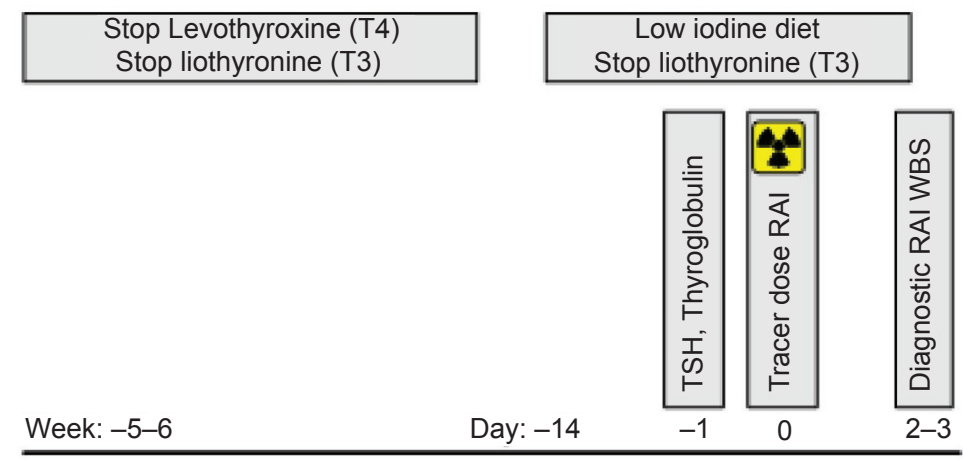

B. rhTSH - stimulated diagnostic WBS and Tg

\begin{tabular}{|c|c|c|c|}
\hline \multicolumn{3}{|c|}{ Low iodine diet } & \\
\hline & 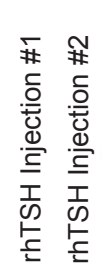 & 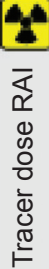 & 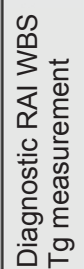 \\
\hline Day: -14 & 12 & 3 & 5 \\
\hline
\end{tabular}

Figure 2 Schedules for diagnostic radioiodine whole body scan and thyroglobulin determonation. Abbreviations: WBS, whole body scan;Tg thyroglobulin; T4, levothyroxine; T3, liothyronine; RAl, radioiodine; rhTSH, recombinant human thyroid stimulating hormone.

Each vial of thyrotropin alfa contains $1.1 \mathrm{mg}$ of rhTSH estimated by in vitro studies to contain 4 to $12 \mathrm{IU} / \mathrm{mg}$. Immediately prior to use, it is reconstituted in $1.2 \mathrm{~mL}$ of sterile water producing a solution with a concentration of $0.9 \mathrm{mg} / \mathrm{mL}$ (3.6-10.8 IU). Two doses of thyrotropin alfa $0.9 \mathrm{mg}(1.0 \mathrm{~mL})$ are administered by intramuscular injection to the buttock, approximately 24 hours apart. For RAI imaging or remnant ablation, RAI is administered 24 hours after the second rhTSH dose and for diagnostic purposes, Tg levels should be measured 72 hours after the last dose (Thyrogen ${ }^{\circledR}$ package insert, Genzyme Corporation, Figures 1 and 2). Subcutaneous injection has been studied in a limited number of patients (Taieb et al 2004) and is an alternative for patients in whom intramuscular injections are contraindicated.

Pharmacokinetics parameters of rhTSH administration were evaluated in a phase I/II study of 19 patients with welldifferentiated thyroid cancer on suppressive levothyroxine doses. Patients were given a variety of doses ranging from 10 to 40 IU injected IM for 1 to 3 days, and RAI uptake and $\mathrm{Tg}$ levels were compared with those after THW. Mean peak TSH concentrations occurred 2 to 8 hours after each injection; after the $10 \mathrm{IU}$ dose, peak mean TSH was $127 \pm 19 \mathrm{mU} / \mathrm{L}$ and elevated TSH persisted for at least 48 hours after the dose (Meier et al 1994). The mean apparent elimination half-life was $25 \pm 10$ hours (Thyrogen ${ }^{\circledR}$ package insert, Genzyme Corporation). This and subsequent pharmacodynamic studies assessing the diagnostic use of rhTSH in thyroid cancer, showed that the lower dose of 10 IU was essentially as efficacious and had fewer side effects than higher doses of 30 or $40 \mathrm{IU}$ and that a regimen of $0.9 \mathrm{mg}$ doses two days in a row results in 3-4 days of serum TSH concentration greater than or equal to $25 \mathrm{mU} / \mathrm{L}$ (Ladenson et al 1997; Haugen et al 1999).

Studies evaluating other factors affecting the pharmacokinetics have subsequently been done, with some showing that peak TSH levels in adults are inversely related to body weight (Zanotti-Fregonara et al 2007), body mass index and body surface area (Vitale et al 2003) but others showing no such relationship (Montesano et al 2007) and one study demonstrating a positive relationship with age (Montesano et al 2007). However, the clinical relevance of such variations has not been demonstrated and no dose adjustment is recommended based on body weight or age. Although not FDA approved for use in children, studies in children report similar TSH levels to adults, suggesting 
that dose adjustment is also not needed in this situation (Iorcansky et al 2005; Hoe et al 2006).

\section{rhTSH in the diagnostic evaluation of thyroid cancer}

Phase I/II studies demonstrated that rhTSH stimulated iodine uptake into thyroid cancer tissue and Tg production (Meier et al 1994), and two phase III studies demonstrated efficacy for identification of residual/recurrent disease by RAI WBS (Ladenson et al 1997; Haugen et al 1999). In the first phase III study of 127 patients, rhTSH resulted in equivalent or superior RAI WBS performed after 78 to $148 \mathrm{MBq}(2-4 \mathrm{mCi})$ ${ }^{131} \mathrm{I}$ in $86 \%$ of evaluations compared with THW. However, the rhTSH-stimulated scans were more frequently poorly visualized, thought to be due to more rapid renal clearance of iodine in the euthyroid state (Ladenson et al 1997). Out of 35 patients evaluated for a Tg response, 15 demonstrated a rise to $>5 \mathrm{ng} / \mathrm{mL}$ after either rhTSH (13/15) or THW (14/15). Thyroglobulin levels peaked at 72 to 96 hours after the first dose of rhTSH.

The second phase III study of 229 patients compared two dosing regimens, utilized a higher RAI tracer dose (148 MBq (4 mCi) ${ }^{131} \mathrm{I}$ in all patients) and measured $\mathrm{Tg}$ and thryoglobulin antibodies in all patients (Haugen et al 1999). Considering rhTSH RAI scans in both arms, $93 \%$ of 220 evaluable scans after rhTSH were concordant with or superior to those done under THW $(\mathrm{p}=0.108)$. Further, among patients with no interfering $\mathrm{Tg}$ antibodies and using a cut-off of $2 \mathrm{ng} / \mathrm{mL}$, there was $100 \%$ sensitivity of a rhTSHstimulated $\mathrm{Tg}$ to detect cervical lymph node and distant metastases and 52\% sensitivity to detect residual thyroid remnant (similar to THW sensitivity of 56\%). This study also demonstrated that the efficacy with a two injection regimen was equivalent to a regimen of three injections over 9 days. It was on the basis of these studies that Thyrogen ${ }^{\circledR}$ achieved FDA approval as an adjunctive diagnostic tool for Tg testing with or without RAI scanning in evaluation of patients with thyroid cancer.

Reproducibility of rhTSH testing has been evaluated in only one study of 23 patients with no evidence of disease by RAI scanning, Tg measurements or clinical evaluation. (Niederkohr and McDougall 2007) The time interval between the two rhTSH-stimulated evaluations was 41 months. Peak serum TSH was $>50 \mathrm{mU} / \mathrm{L}$ in all evaluations and $>100 \mathrm{mU} / \mathrm{L}$ in $73 \%$ of studies. There was good correlation of the 48 hour RAI uptake between the two studies $(\mathrm{r}=0.85, \mathrm{p}=0.0001)$, peak serum TSH $(r=0.69, p=0.0003)$ and $\operatorname{Tg}(r=0.81$, $\mathrm{p}<0.0001)$. However, since most evaluations showed very low RAI uptake and low Tg levels (mean $2.05 \mathrm{ng} / \mathrm{mL}$ ), it is difficult to extrapolate these results to patients with positive evaluations.

Recognition of the ability of rhTSH-stimulated Tg measurement to identify residual/recurrent thyroid cancer with high accuracy and the potential for avoiding the morbidity of hypothyroidism associated with THW has led to a shift in the paradigm for the follow-up evaluation of patients with thyroid cancer. It is now clear that stimulated TG levels (usually combined with a neck ultrasound) represent the most sensitive means of detecting residual or recurrent thyroid cancer. Specifically, in patients where Tg measurement was possible (eg, those lacking antithyroglobulin antibodies), the accuracy of rhTSH-stimulated Tg evaluation met or exceeded that of rhTSH-stimulated or even THW RAI WBS (Cailleux et al 2000; Mazzaferri et al 2003; Pacini et al 2003; Torlontano et al 2003; Schlumberger et al 2004). Additionally, several studies demonstrated that in low risk patients, if the first rhTSH-stimulated Tg was undetectable, the likelihood of thyroid cancer recurrence over 2 to 4 years was exceedingly small (Cailleux et al 2000; Baudin et al 2003; Castagna et al 2008; Crocetti et al 2008). Based on this, the ATA and ETA guidelines recommend against RAI WBS in the routine follow-up of low-risk patients without evidence of disease (clinically and based on unstimulated $\mathrm{Tg}$ or ultrasound). Rather, unstimulated Tg and neck ultrasonography are routine in follow-up, with further stimulated Tg measurements and additional evaluation if indicated. Recently, highly sensitive (eg, functional sensitivity of $0.1 \mathrm{ng} / \mathrm{mL}$ ) unstimulated $\mathrm{Tg}$ measurements have been reported to be equally predictive of disease (Iervasi et al 2007; Smallridge et al 2007), albeit in small cohorts and with only short follow-up. As the reliability and long-term predictive value of highly sensitive Tg measurements improves, this may eventually supplant stimulated Tg measurements for thyroid cancer surveillance.

One additional aspect to be considered in the evaluation of patients with thyroid cancer is the utility of rhTSH in patients undergoing 18-fluorodeoxyglucose (18-FDG) positron emission tomography (PET) scanning. Detection of lesions by PET scanning is often complementary to that of RAI scanning, with more aggressive lesions having lost iodine avidity but demonstrating significant glucose uptake. In addition, PET scanning has a role in predicting the biologic behavior of lesions, with mortality closely related to volume of PET+ disease (Wang et al 2000; Robbins et al 2006b) which may influence therapeutic decisions. Several studies have demonstrated enhanced 
lesion detection, SUV levels and reduced background in PET scans performed after rhTSH stimulation, reviewed recently by Leboulleux et al (2007), presumably due to increased GLUT1 synthesis and glucose transport stimulated by TSH action. However, the utility of the incremental improvement in PET performance with rhTSH stimulation for affecting clinical decision making is not clear.

\section{rhTSH for thyroid remnant ablation}

The literature reflects a growing experience with rhTSH for thyroid remnant ablation, summarized in Table 1, which details efficacy results from studies that included 10 or more patients. Studies evaluating rhTSH for thyroid remnant ablation include retrospective series (with historical or nonrandomized THW controls), prospective consecutively enrolling studies (Robbins et al 2001; Pacini et al 2002; Robbins et al 2002b; Barbaro et al 2003; Barbaro et al 2006; Pilli et al 2007; Rosario et al 2008; Tuttle et al 2008) and two randomized trials which compared the efficacy and safety of rhTSH stimulation during levothyroxine treatment with conventional THW remnant ablation (Pacini et al 2006a; Taieb et al 2008). Only one of the randomized studies and one uncontrolled study have reported clinical follow-up beyond one year (Elisei et al 2007; Tuttle et al 2008). Most studies utilized the schedule of rhTSH administration illustrated in Figure 1c.

One of the randomized trials (Taieb et al 2008) compared subjects who all received $3.7 \mathrm{GBq}(100 \mathrm{mCi}){ }^{131} \mathrm{I}$ after rhTSH preparation or THW. Subjects received levothyroxine therapy for 1 week and then were randomized to either rhTSH $(n=36)$ or THW $(n=35)$ preparation for RAI ablation. For patients randomized to rhTSH preparation, levothyroxine was continued and rhTSH $0.9 \mathrm{mg}$ was administered intramuscularly on 2 consecutive days. Twenty-four hours after the final rhTSH injection, the ablative dose of RAI was administered. Patients randomized to THW discontinued levothyroxine for 5 weeks, then received the RAI dose. Ablation outcome was evaluated at 9 months post ablation with a rhTSH-stimulated RAI scan and $\mathrm{Tg}$ measurement and neck ultrasonography. No uptake was visible on scans in $72 \%$ of patients prepared by rhTSH stimulation and $91 \%$ of those prepared by THW ( $\mathrm{p}=0.04)$. However, most of the patients had a trivial amount of uptake, with $95 \%$ of all rhTSH stimulated and $100 \%$ of THW prepared patients having a RAI scan with $<0.1 \%$ uptake $(\mathrm{p}=0.49)$. A third criteria for ablation success was the rhTSH-stimulated Tg measurement,

Table I Studies evaluating the effectiveness of rhTSH or thyroid hormone withdrawal preparation for radioiodine ablation of thyroid remants

\begin{tabular}{|c|c|c|c|c|c|c|}
\hline \multirow[t]{2}{*}{$\begin{array}{l}\text { Author, Year } \\
\text { of publication }\end{array}$} & \multicolumn{2}{|c|}{$\begin{array}{l}\text { No of } \\
\text { patients }\end{array}$} & \multirow[t]{2}{*}{${ }^{|3|} \mid$ dose } & \multicolumn{2}{|c|}{$\begin{array}{l}\text { Ablation outcome (visible } \\
\text { uptake on RAI WBS) }\end{array}$} & \multirow[t]{2}{*}{ Comments } \\
\hline & rhTSH & THW & & rhTSH & THW & \\
\hline Robbins 200I & 10 & - & I.I-9.3 GBq (30-250 mCi) & $100 \%$ & - & \\
\hline Robbins 2002b & 45 & 42 & $\begin{array}{l}\text { 4.I GBq }(I 10 \mathrm{mCi}) \mathrm{rhTSH} \\
4.8 \mathrm{GBq}(129 \mathrm{mCi}) \mathrm{THW}\end{array}$ & $84 \%$ & $81 \%$ & \\
\hline Pacini 2002 & 70 & 50 & I.I GBq (30 mCi) & $54 \%$ & $84 \%$ & $\begin{array}{l}{ }^{|3|} \mid \text { given on day } 4 \text {; additional } 42 \text { patients } \\
\text { prepared with thyroid hormone withdrawal } \\
\text { and rhTSH had a } 79 \% \text { ablation success }\end{array}$ \\
\hline Barbaro 2003 & 16 & 24 & I.I GBq (30 mCi) & $88 \%$ & $75 \%$ & Off $\mathrm{LT} 4 \times 4$ days \\
\hline Barbaro 2006 & 52 & 41 & I.I GBq (30 mCi) & $77 \%$ & $76 \%$ & Off $\mathrm{LT} 4 \times 4$ days \\
\hline Pacini 2006a & 32 & 28 & $3.7 \mathrm{GBq}(100 \mathrm{mCi})$ & $75 \%$ & $86 \%$ & Randomized \\
\hline Pilli 2007 & 72 & - & $1.9-3.7 \mathrm{GBq}(50-100 \mathrm{mCi})$ & $89 \%$ & - & \\
\hline Tuttle 2008 & 220 & 7I & $\begin{array}{l}\text { 4.0 GBq (109 mCi) rhTSH } \\
3.8 \mathrm{GBq}(103 \mathrm{mCi}) \mathrm{THW}\end{array}$ & $83 \%$ & $76 \%$ & \\
\hline Rosario 2008 & 30 & 64 & $3.7 \mathrm{GBq}(100 \mathrm{mCi})$ & $90 \%$ & $80 \%$ & $\begin{array}{l}\text { Ablation outcome criteria: Stim } \mathrm{Tg}<\mathrm{I} \\
\text { and negative neck ultrasonography }\end{array}$ \\
\hline Taieb 2008 & 36 & 35 & 3.7 GBq (I00 mCi) & $72 \%$ & $91 \%$ & Randomized \\
\hline
\end{tabular}

Abbreviations: rhTSH, recombinant human thyroid stimulating hormone; THW, thyroid hormone withdrawal; RAI, radioiodine; WBS, whole body scan; LT4, levothyroxine; $\mathrm{Tg}$, thyroglobulin. 
which was $<0.8 \mathrm{ng} / \mathrm{mL}$ in $92 \%$ of rhTSH-stimulated ablations and $97 \%$ of hypothyroid ablations $(\mathrm{p}=0.61)$.

The other randomized trial (Pacini et al 2006a) also compared subjects who all received $3.7 \mathrm{GBq}(100 \mathrm{mCi})$ ${ }^{131} \mathrm{I}$ after TSH stimulation preparation by rhTSH or THW. In this study, 33 patients were randomized to the euthyroid (rhTSH) group and received levothyroxine therapy for 4 to 6 weeks until their TSH was $5 \mathrm{mU} / \mathrm{L}$ or less. RhTSH $0.9 \mathrm{mg}$ was then given on 2 consecutive days, and 24 hours after the final injection, the ablative dose of RAI was administered. Thirty patients were randomized to the hypothyroid group and had levothyroxine replacement withheld, and after 4 to 6 weeks when the TSH was least $25 \mathrm{mU} / \mathrm{L}$, they then received the ablative RAI dose. On a rhTSH-stimulated RAI scan 8 months after treatment, 24 of 32 evaluable euthyroid patients (75\%) and 24 of 28 hypothyroid evaluable patients $(86 \%)$ had no visible uptake $(\mathrm{p}=0.3)$. Using a level of rhTSH-stimulated serum Tg less than $2 \mathrm{ng} / \mathrm{mL}$ at the 8-month point as a measure of successful ablation, 23 of 24 evaluable euthyroid patients (96\%) and 18 of 21 evaluable hypothyroid patients $(85 \%)$ were successfully ablated $(\mathrm{p}=0.2)$.

In this same study, 61 of these patients were followed for a median of 3.7 years after their ablation. During that time, 7 patients had additional therapy (surgery or RAI), 3 in the rhTSH ablated and 4 in the hypothyroid group. Follow-up evaluations revealed equivalent numbers of patients with "visible" (but $<0.1 \%$ ) uptake on RAI WBS and positive ( $>2 \mathrm{ng} / \mathrm{mL}$ ) stimulated Tg measurements (1 in each group) (Elisei et al 2007).

The only other study reporting outcome data beyond one year is that of a large series of 394 patients treated with either rhTSH $(n=320)$ or THW $(n=74)$ preparation at Memorial Sloan Kettering Cancer Center (Tuttle et al 2008). In this series, the choice of preparation was uncontrolled, and patients underwent ablation with the RAI dose determined according to clinical features, histologic findings, intraoperative findings, risk of recurrence and results of a diagnostic I-123 WBS, regardless of method of preparation (rhTSH or THW). Ablative RAI doses ranged from $2.7-3.7 \mathrm{GBq}(75-100 \mathrm{mCi}){ }^{131} \mathrm{I}$ for intrathyroidal papillary thyroid carcinoma, 3.7 to $5.5 \mathrm{GBq}(100-150 \mathrm{mCi})$ for patients with cervical lymph node metastases and $>5.5 \mathrm{GBq}$ $(150 \mathrm{mCi})$ if locally aggressive disease or known distant metastases were present. Patients who underwent rhTSHstimulated ablation received a median of $109 \mathrm{mCi}$ compared with THW patients who received a median of $103 \mathrm{mCi}^{131} \mathrm{I}$ $(\mathrm{p}<0.01)$, median age was slightly higher in the rhTSH group (46.5 years vs 44.0 years, $\mathrm{p}=0.03$ ) and median follow-up duration was shorter (27 months vs 45 months, $\mathrm{p}<0.001)$; other characteristics of the patients were not different between the groups. Ablation success was evaluated in 291 of the subjects who underwent a follow-up rhTSH-stimulated RAI WBS at 12 to 18 months. Successful ablation defined as no visible uptake on the RAI WBS was achieved in $83 \%$ of rhTSH stimulated ablations and $76 \%$ of THW prepared patients. Using a definition of $<0.1 \%$ uptake, successful ablation was achieved in $95 \%$ of those undergoing rhTSH ablation and in $90 \%$ of THW prepared patients $(\mathrm{p}=0.35)$. Suppressed and stimulated Tg levels were not different between the groups at the 12 to 18 month follow-up; $68.6 \%$ of rhTSH-prepared patients had a stimulated $\mathrm{Tg}<2 \mathrm{ng} / \mathrm{mL}$ compared with $61.9 \%$ of THW prepared patients ( $\mathrm{p}$-value not significant, Tuttle, personal communication).

Follow-up of this cohort was for a median of 2.5 years and the authors reported four clinical outcomes: no clinical evidence of disease (NCED: negative rhTSH WBS, no clinical recurrence, suppressed $\mathrm{Tg}<2 \mathrm{ng} / \mathrm{mL}$ and stimulated $<10 \mathrm{ng} / \mathrm{mL}$ ), clinical recurrence (new disease after a period of NCED), persistent disease (suppressed $\mathrm{Tg}>2 \mathrm{ng} / \mathrm{mL}$ or stimulated $>10 \mathrm{ng} / \mathrm{mL} 1$ year after ablation, persistent anatomic disease, new metastasis within six months of ablation or known distant metastases at diagnosis) and thyroid bed uptake only (persistent at 12- to 18-month follow-up with no other Tg or ultrasonographic evidence of disease). There were more treatment failures in patients prepared by THW ( $\mathrm{p}=0.02)$, but equivalent numbers of patients in the two groups when considering only patients without distant metastases. This lends reassurance that the initial favorable response to rhTSH-stimulated remnant ablation is durable.

In summary, data on almost 600 patients have been reported in several uncontrolled studies and two relatively small randomized controlled trials, demonstrating that rhTSH stimulation for RAI thyroid remnant ablation is successful in about $80 \%$ to $90 \%$ of patients, comparable to rates seen with THW preparation. In December of 2007, the FDA approved Thyrogen ${ }^{\circledR}$ for use "as an adjunctive treatment for RAI ablation of thyroid tissue remnants in patients who have undergone a near-total or total thyroidectomy for well-differentiated thyroid cancer and who do not have evidence of metastatic thyroid cancer." It should be noted, that the patients who participated in these studies were generally patients with low stage disease, and because of concern about lower 
RAI uptake from early studies with rhTSH, care should be taken when evaluating patients for selection for rhTSH stimulated ablation.

\section{Optimal radioiodine dose and other factors important for successful thyroid remnant ablation under rhTSH stimulation}

The issue of the minimum adequate dose required for remnant ablation has been a controversial one even prior to the use of rhTSH preparation. The efficacy of doses lower than $3.7 \mathrm{GBq}(100 \mathrm{mCi}){ }^{131} \mathrm{I}$ for ablation of thyroid remnants with rhTSH preparation has been examined in four studies and is compared to that reported in studies using greater than $3.7 \mathrm{GBq}(100 \mathrm{mCi}){ }^{131} \mathrm{I}$, all of which are summarized in Table 2. One of these was a randomized trial that compared $1.9 \mathrm{GBq}(50 \mathrm{mCi})$ with $3.7 \mathrm{GBq}$ (100 mCi) (Pilli et al 2007). This study as well as 2 of the 3 uncontrolled studies utilizing $1.1 \mathrm{GBq}(30 \mathrm{mCi})$ (Pacini et al 2002; Barbaro et al 2003; Barbaro et al 2006) reported $77 \%$ to $89 \%$ ablation rates, defined as no visible uptake on a WBS, similar to the 6 studies administering $3.7 \mathrm{GBq}(100 \mathrm{mCi})$ or more which had ablation rates from $72 \%$ to $89 \%$ (Robbins et al 2002b; Pacini et al 2006a; Rosario et al 2008; Taieb et al 2008; Tuttle et al 2008). The third uncontrolled study of $1.1 \mathrm{GBq}(30 \mathrm{mCi})$ found a lower ablation rate (54\%); however, the investigators utilized a different schedule of rhTSH administration, which may have compromised iodine uptake.

Compared with THW, renal clearance of RAI is not reduced when rhTSH is used. For this reason, the use of a low iodine diet to deplete iodine stores and/or evaluation of urinary iodine excretion has been routinely done in these studies. An additional source of iodine is that contained in thyroid hormone replacement preparations. Therefore, the impact of continuing thyroid hormone preparations on the efficacy of rhTSH ablation has also been studied (Barbaro et al 2003). This study demonstrated that omission of levothyroxine for 4 days reduced urinary iodine, but urinary iodine was not different in another study between hypothyroid and euthyroid subjects where levothyroxine was continued (Pacini et al 2006a). Further, in these studies, it did not appear that discontinuing thyroid hormone improved ablation rates compared to studies that allowed patients to continue their thyroid hormone replacement. However, no study has evaluated this question in a single study in a randomized fashion.
In summary, the limited data available suggests that doses of RAI less than $3.7 \mathrm{GBq}(100 \mathrm{mCi}){ }^{131} \mathrm{I}$ may indeed be as efficacious as higher doses. Short term discontinuation of thyroid hormone preparations does not appears to improve ablation rates, but may warrant evaluation in additional patient populations in a randomized study. Finally, the timing of RAI administration in relation to rhTSH stimulation may be a critical factor.

\section{Logistic issues with rhTSH stimulated thyroid remnant ablation}

The studies summarized above generally used a standard schedule of administering rhTSH on days 1 and 2, then giving the ablative RAI on day 3 when TSH levels are at their peak, which should be optimal for RAI uptake into the thyroid gland. However, this schedule is problematic if one needs to obtain a diagnostic scan before administering the therapeutic RAI dose. When a diagnostic scan is indicated to assist in ablative dosage selection or as a baseline for comparison to future scans, various schedules have been proposed to circumvent this problem. These include administering a tracer dose of ${ }^{123} \mathrm{I}$ (which has a shorter half-life) on day 3, which allows an ${ }^{123}$ I diagnostic scan to be performed prior to an ${ }^{131} \mathrm{I}$ ablation dose given the same day. Alternatively some clinicians perform either an ${ }^{123} \mathrm{I}$ or ${ }^{131} \mathrm{I}$ scan on days 3 and 4, and delay administration of the ablative ${ }^{131} \mathrm{I}$ dose until day 4, 2 days after the last rhTSH dose. This has the disadvantage of delaying RAI therapy until day 4 when TSH levels have decreased significantly, thereby potentially lowering treatment efficacy. Only one study has specifically reported ablation rates with this schedule and found that only $54 \%$ of patients were ablated when given $1.1 \mathrm{GBq}(30 \mathrm{mCi}){ }^{131} \mathrm{I}$ on day 4 after rhTSH (Pacini et al 2002). Whether this lower rate was related to the lower RAI dose or the later RAI administration is not clear, however, other studies with $1.1 \mathrm{GBq}(30 \mathrm{mCi}){ }^{131} \mathrm{I}$ (including studies from the same group) have significantly higher ablation rates (see previous section and Table 2 for details). The value of the diagnostic scan prior to ablation has been questioned and 1 study has demonstrated that the diagnostic scan rarely assists in managing the patient (Mandac et al 2008). Most providers feel the value of the diagnostic scan is minimal and perform only a post-therapy scan approximately 1 week after the ablative dose. Alternatively, if the diagnostic scan is felt to be critical to decision-making, a second course of rhTSH stimulation can be administered the week following the diagnostic scan, ensuring adequate TSH stimulation for remnant ablation (as show in Figure 1d). 


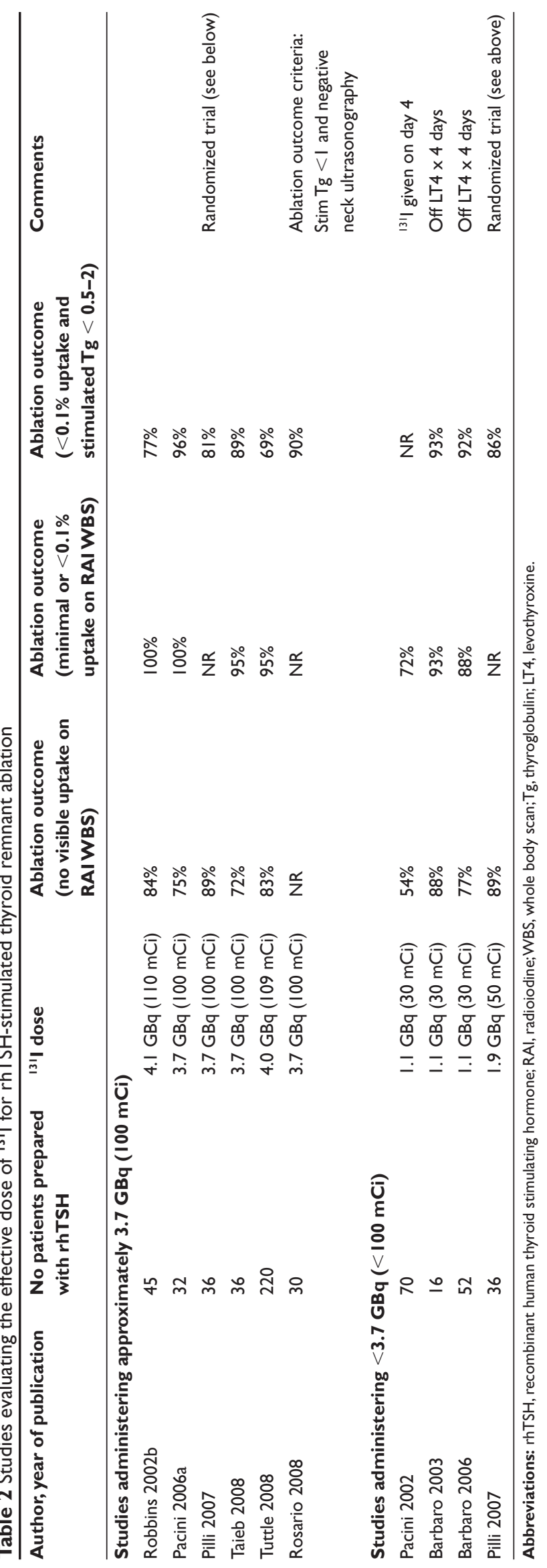

A second logistic issue with rhTSH stimulated ablation is the timing of the measurement of the rhTSH-stimulated $\mathrm{Tg}$ levels. Several studies have shown the predictive value of the post-thyroidectomy, preablative stimulated Tg level (Grunwald et al 1996; Toubeau et al 2004; Kim et al 2005). However, pharmacodynamic studies of rhTSH for diagnostic uses demonstrated that the peak $\mathrm{Tg}$ level in response to rhTSH occurred on day 5 after the 2 rhTSH injections (Ladenson et al 1997; Haugen et al 1999). This is after the ablative dose of RAI, which could impact Tg levels on the basis of radiationinduced tumor lysis. One study examined the effect of this intervening ablative dose of RAI on Tg levels and found that Tg levels increased after RAI therapy due to acute radiation effects (Taieb et al 2006). Because of the two simultaneous stimuli to Tg levels, rhTSH and RAI tumor destruction, this paradigm would not result in Tg levels that would be comparable to values obtained in diagnostic settings. Other clinicians draw a $\operatorname{Tg}$ on day 3, just before the ablative RAI dose, but this is less predictive because of the difference in timing of the $\mathrm{Tg}$ level in relationship to rhTSH. Further studies will be needed to determine if this measurement has any clinical utility.

\section{Utility of rhTSH for radioiodine treatment of metastatic thyroid cancer}

The first report of RAI treatment of metastatic thyroid cancer using rhTSH stimulation dates back to 1997 (Rudavsky and Freeman 1997). Concern about the efficacy of this approach stems from observations of lower apparent RAI uptake observed in the early phase diagnostic studies, thought to be due to more rapid iodine clearance in euthyroid patients (Park et al 1996; Ladenson et al 1997). However, the impact of this biologic measure on the ultimate clinical outcome, effective treatment of the metastatic deposits, is less clear. Although lower iodine uptake has been shown to lack clinical significance for thyroid remnant ablation, described in the previous section, it may be more relevant in treating metastatic disease due to the impaired iodine uptake and organification observed in carcinomatous tissue compared with normal thyroid tissue (Schlesinger et al 1989). Thyrogen ${ }^{\circledR}$ is FDA approved as an adjunct to RAI treatment of metastatic thyroid cancer only in patients who are either unable to mount an adequate endogenous TSH response to THW or in whom THW is medically contraindicated, as options are otherwise limited in that patient population. Although there are no randomized trials comparing rhTSH stimulated RAI treatment to THW prepration, data from this "compassionate use" population and other case series (Luster et al 2000; Mariani et al 2000; 
Lippi et al 2001; Pellegriti et al 2001; Berg et al 2002; de Keizer et al 2003; Jarzab et al 2003; Robbins et al 2006a), summarized in Table 3, provide some information about the effectiveness of this approach. Unfortunately, the literature is heterogeneous and limited in particular by the lack of outcome data. Further, the interpretation of this literature is difficult given the relative lack of comparable data for the efficacy of RAI therapy prepared by THW, with reports ranging from 20\% to 90\% (Maxon et al 1992; Pacini et al 1994; Alzahrani et al 2002; Robbins et al 2002a; Dam et al 2004; Rosario et al 2004; Kloos and Mazzaferri 2005).

Despite these limitations, almost all of the listed studies report uptake on post-therapy scans in a majority of patients, providing reasonable evidence for rhTSH stimulation of iodine uptake in metastatic deposits. Further, two studies compare the rhTSH scans to prior hypothyroid scans favorably, with concordant or superior rhTSH scans in $82 \%$ to $90 \%$ of patients (Lippi et al 2001; Jarzab et al 2003). However, even though some uptake is observed after rhTSH, the concern remains that since lower RAI uptake has fairly consistently been observed in several studies (Park et al 1996; Ladenson et al 1997; Pacini et al 2002; Luster et al 2003; Hanscheid et al 2006; Potzi et al 2006; Vaiano et al 2007), the radiation dose to the tumor may be reduced in patients treated with rhTSH. This has been examined in several dosimetric studies, summarized in Table 4. The methods and reported parameters (eg, initial dose rate, effective half-life, residence time, cumulative activity) across the studies are quite heterogeneous. In addition, the conclusions in regard to effective radiation dose are mixed, with 3 of 6 studies showing a reduced radiation dose to the thyroid remnant or tumor (Pacini et al 2002; Potzi et al 2006; Vaiano et al 2007), 2 showing an increased radiation dose (Luster et al 2003; Hanscheid et al 2006) and 1 estimating the dose to be the same as historical hypothyroid-prepared patients (de Keizer et al 2003). Also potentially concerning is that the studies summarized in Table 3 include few reports of complete remission with rhTSH-stimulated treatment, even by surrogate markers such as Tg or follow-up RAI scans, and there is even a low rate of partial responses. However, in many of the series, the patient populations had very advanced disease, such that complete or partial responses might not be expected, and stable disease would be considered to represent a clinical benefit to the patient.

\section{Safety and tolerability}

In clinical trials rhTSH for both diagnostic and therapeutic purposes, the incidence of side effects was low.
Combined data from clinical trials leading to FDA approval reveal the most common adverse events to be nausea $(11.9 \%)$ and headache $(7.3 \%)$ (Thyrogen ${ }^{\circledR}$ package insert, Genzyme Corporation). According to the Genzyme package insert, post-marketing experience has shown that administration of rhTSH can cause transient flu-like symptoms for up to 48 hours. Hypersensitivity has also been reported in patients with advanced disease, as manifested by urticaria, rash, pruritis, flushing, and respiratory symptoms. Similar to THW, there are case reports of tumor enlargement, edema, and hemorrhage resulting in paresthesias, hemiplegia, pathologic vertebral fractures, neck edema as well as exacerbation of bone pain seen within 12 to 48 hours of rhTSH administration (Vargas et al 1999; Robbins et al 2000; Braga et al 2001; Lippi et al 2001; Berg et al 2002; Goffman et al 2003; Jarzab et al 2003). For this reason, it is recommended that pretreatment with glucocorticoids be considered in patients with tumors located where transient expansion may compromise vital anatomic structures (eg, CNS and spinal metastases, bulky neck metastases). It is also recommended that patients who have extensive functional thyroid tissue or cardiac conditions (for whom rhTSH-induced stimulation of thyroid hormone production causing hyperthyroidism could have serious consequences) be hospitalized for administration and observation.

One potential advantage to rhTSH stimulation may be lower radiation exposure. Since there is reduced renal clearance of iodine and longer retention of the RAI in hypothyroid patients, preparation with rhTSH allows patients to remain euthyroid and potentially clear their radiation dose faster. Several recent studies have examined this issue and are summarized in Table 4. The methods across the studies are quite heterogeneous and not all studies reported both blood and whole body exposure. However, all studies that report either blood or red marrow doses, whole body retention times or residence times show the radiation exposure to be reduced by $10 \%-35 \%$ when prepared with rhTSH preparation rather than THW (Pacini et al 2002; de Keizer et al 2003; Luster et al 2003; Menzel et al 2003; de Keizer et al 2004; Hanscheid et al 2006; Potzi et al 2006; Vaiano et al 2007).

\section{Quality of life}

As mentioned previously, rhTSH was developed to avoid the consequences of prolonged hypothyroidism, and the negative impact of symptoms of hypothyroidism on patient quality of life. The impact of treatment on quality of life has been 
Table 3 Studies evaluating the effectiveness of rhTSH for ${ }^{131}$ treatment of metastatic disease after prior thyroidectomy

\begin{tabular}{|c|c|c|c|c|c|c|}
\hline \multirow{2}{*}{$\begin{array}{l}\text { Author, year } \\
\text { of publication }\end{array}$} & \multirow{2}{*}{$\begin{array}{l}\text { No of patients } \\
\text { (No treatments, } \\
\text { if }>\text { I/patient) }\end{array}$} & \multirow[t]{2}{*}{ |31| dose } & \multicolumn{3}{|c|}{ Treatment outcome } & \multirow[t]{2}{*}{ Comments } \\
\hline & & & $\begin{array}{l}\text { Uptake on } \\
\text { post-therapy } \\
\text { scan }\end{array}$ & Tg response & $\begin{array}{l}\text { Clinical/imaging } \\
\text { response }\end{array}$ & \\
\hline Luster 2000 & $11(16)$ & $\begin{array}{l}\mathrm{I}-7.4 \mathrm{GBq} \\
(27-200 \mathrm{mCi})\end{array}$ & NR & $\begin{array}{l}\text { 5/II PR } \\
\text { 2/9 SD } \\
3 / 11 \mathrm{SD}\end{array}$ & $\begin{array}{l}2 / I I P R \\
3 \text { dead of PD }\end{array}$ & $\begin{array}{l}\text { Advanced disease in } 90 \% \mathrm{Tg} \\
\text { response: }>30 \% \text { decrease }\end{array}$ \\
\hline Mariani 2000 & 8 & & $7 / 8$ & & & $\begin{array}{l}\text { No uptake due to iodine } \\
\text { contamination in I patient }\end{array}$ \\
\hline Pellegriti 200I & 6 & $3.7 \mathrm{GBq}(100 \mathrm{mCi})$ & $4 / 6$ & NR & $\begin{array}{l}\text { I/4 PR } \\
\text { 3/4 SD }\end{array}$ & $\begin{array}{l}2 \text { patients with negative } \\
\text { WBS also had low } \\
\text { stimulated Tg; may have } \\
\text { been with no or no } \\
\text { significant disease }\end{array}$ \\
\hline Lippi 200I & 12 & $\begin{array}{l}0.1-0.11 \mathrm{GBq} / \mathrm{kg} \\
2.7-3.0 \mathrm{mCi} / \mathrm{kg}\end{array}$ & $12 / 12$ & $\begin{array}{l}\text { 4/10 PR } \\
\text { 2/10 SD } \\
4 / 10 \mathrm{PD}\end{array}$ & $2 / 5$ & $\begin{array}{l}\text { Comparison to prior THW } \\
\text { scan concordant in } 67 \% \text {, } \\
\text { superior in } 33 \%\end{array}$ \\
\hline Berg 2002 & $8(\mathrm{II})$ & $4.0 \mathrm{GBq}(\mathrm{I} 08 \mathrm{mCi})$ & $9 / 11$ & $\begin{array}{l}\text { I/7 PR } \\
3 / 7 \mathrm{SD} \\
3 / 7 \mathrm{PD}\end{array}$ & $\begin{array}{l}5 / 7 \mathrm{PR} \\
2 \mathrm{NED}\end{array}$ & \\
\hline De Keizer 2003 & 16 & $7.4 \mathrm{GBq}(200 \mathrm{mCi})$ & $18 / 19$ & $\begin{array}{l}\text { 3/II PR } \\
\text { 2/IISD } \\
6 / 1 I P D\end{array}$ & NR & $\begin{array}{l}\text { Tg Response: }>25 \% \\
\text { decrease, increase }\end{array}$ \\
\hline Jarzab 2003 & $31(54)$ & $\begin{array}{l}3.7-7.4 \mathrm{BGq} \\
(100-200 \mathrm{mCi})\end{array}$ & $25 / 30$ & $\begin{array}{l}\text { Imaging and } \mathrm{Tg} \\
\text { I/47 CR } \\
\text { I2/47 PR } \\
\text { I9/47 SD } \\
\text { I4/47 PD }\end{array}$ & esponse & $\begin{array}{l}\text { Negative uptake reported } \\
\text { to be due to CR in } 3 \text {, } \\
\text { dedifferentiation in } 2 \\
\text { Comparison to prior } \\
\text { hypothyroid scan con- } \\
\text { cordant in } 67 \% \text {, superior } \\
\text { in } 15 \% \text {, inferior in } 19 \% \\
\text { (attributed to clinical causes, } \\
\text { not differences in rhTSH vs } \\
\text { THW preparation) } \\
\text { Comparison to prior } \\
\text { THW outcome of therapy } \\
\text { identical in } 52 \% \text {; superior in } \\
32 \% \text {, inferior in } 16 \%\end{array}$ \\
\hline Robbins 2006a & II 5 (NR) & NR & $\begin{array}{l}105 / 115 \\
\text { Diagnostic or } \\
\text { post-therapy }\end{array}$ & $48 \%-73 \%$ PR & $\begin{array}{l}25 \% \text { improved } \\
55 \%-60 \% \text { no } \\
\text { change } \\
15 \%-20 \% \text { worse }\end{array}$ & \\
\hline
\end{tabular}

Abbreviations: rhTSH, recombinant human thyroid stimulating hormone; Tg, thyroglobulin; NR, not reported; PR, partial response; SD, stable disease; PD, progressive disease; WBS, whole body scan; THW, thyroid hormone withdrawal; NED, no evidence of disease; CR, complete remission.

assessed in several of the randomized prospective efficacy trials comparing rhTSH with THW. In all studies that report it, quality of life by a variety of measures (hypothyroid symptoms and signs by the self-reported Billewicz scale or a validated hypothyroid clinical questionnaire; global quality of life by SF-36 health survey or a cancer specific survey; mood by various inventories) reveal increased symptoms and decrements in quality of life with THW preparation that is prevented by preparation with rhTSH instead (Botella-Carretero et al 2003; Giusti et al 2005; 
Table 4 Studies reporting dosimetric evaluation of thyroid remnant, metastatic tumor, blood and whole body radiation exposure after rhTSH compared to thyroid hormone withdrawal preparation

\begin{tabular}{|c|c|c|c|}
\hline Author, year of publication & $\begin{array}{l}\text { No of patients } \\
\text { (No evaluations) }\end{array}$ & $\begin{array}{l}\text { Summary of findings } \\
\text { related to dose to } \\
\text { remnant }\end{array}$ & $\begin{array}{l}\text { Summary of findings } \\
\text { related to blood and whole } \\
\text { body exposure }\end{array}$ \\
\hline Pacini 2002 & 70 rhTSH 42 THW & $\begin{array}{l}\text { Mean initial dose rate I } \\
0.7 \mathrm{~Gy} / \mathrm{h} \text { after rhTSH vs } \\
27.1 \mathrm{~Gy} / \mathrm{h} ; 60.5 \% \text { lower } \\
\text { than THW Cumulative } \\
\text { dose could not be assessed } \\
\text { because effective half-life was } \\
\text { not measured. }\end{array}$ & NR \\
\hline De Keizer 2003, 2004 & $16(19 \mathrm{Rx})$ & $\begin{array}{l}\text { Tumor effective half-life } 65 \mathrm{~h} \text {, } \\
\text { similar to previous report of } \\
79 \mathrm{~h} \text { for THW }\end{array}$ & $\begin{array}{l}\text { Blood dose } 0.23 \mathrm{mGy} / \mathrm{MBq} \\
\text { Red marrow dose } \\
0.16 \mathrm{mGy} / \mathrm{MBq} \text {, below } 2 \mathrm{~Gy} \\
\text { in all patients given } 7.4 \mathrm{GBq} \\
26 \% \text { lower than historical } \\
\text { hypothyroid preparation }\end{array}$ \\
\hline Luster 2003 & 9 & $\begin{array}{l}\text { Tumor effective half-life } \\
\text { longer than THW } \\
\text { Tumor residence time } \\
\text { increased } 5.7 \pm 6.3 \text { fold after } \\
\text { rhTSH }\end{array}$ & $\begin{array}{l}\text { Blood effective half-life } 25 \% \\
\text { shorter, blood dose } 10 \% \text { lower } \\
\text { Whole body exposure } 22 \% \\
\text { lower }\end{array}$ \\
\hline Menzel 2003 & $\begin{array}{l}38 \mathrm{rhTSH}(64 \mathrm{Rx}) \\
103 \mathrm{THW}(163 \mathrm{Rx})\end{array}$ & NR & $\begin{array}{l}\text { Whole body effective half-life } \\
0.43 \text { d after rhTSH vs } 0.54 \mathrm{~d} \text {; } \\
20 \%-25 \% \text { shorter than THW }\end{array}$ \\
\hline Hanscheid 2006 & 33 rhTSH 30 THW & $\begin{array}{l}\text { Remnant effective half-life } \\
68 \mathrm{~h} \text { after rhTSH vs } 48 ; 40 \% \\
\text { longer than THW } \\
\text { Tumor residence time } 1.4 \mathrm{~h} \\
\text { after rhTSH vs } 0.9 ; 60 \% \\
\text { longer than THW }\end{array}$ & $\begin{array}{l}\text { Blood dose } 0.109 \mathrm{mGy} / \mathrm{MBq} \\
\text { after rhTSH vs } 0.167 \mathrm{mGy} / \mathrm{MBq} \text {; } \\
35 \% \text { lower than THW } \\
\text { Whole body residence time } \\
17.3 \text { h after rhTSH vs } 24.1 \mathrm{~h} \text {; } \\
28 \% \text { shorter than THW }\end{array}$ \\
\hline Potzi 2006 & 4 & $\begin{array}{l}\text { Median tumor half-life } 22 \mathrm{~h} \\
\text { after rhTSH vs } 40 \mathrm{hr} \text { THW; } \\
45 \% \text { shorter than THW } \\
\text { Mean cumulative activity } \\
5.6 \mathrm{uCi} / \mathrm{hr} \text { after rhTSH vs } \\
9.5 \mathrm{uCi} / \mathrm{h} ; 41 \% \text { lower activity } \\
\text { than THW }\end{array}$ & \\
\hline Vaiano 2007 & I7 rhTSH 2 I THW & $\begin{array}{l}\text { Mean cumulative activity } \\
0.9 \text { h after rhTSH vs } \mathrm{I} .55 \mathrm{~h} \text {; } \\
40 \% \text { lower than THW }\end{array}$ & $\begin{array}{l}\text { Red marrow dose } 0.06 \mathrm{mGy} / \mathrm{MBq} \\
\text { after rhTSH vs } 0.09 \mathrm{mGy} / \mathrm{MBq} \text {; } \\
33 \% \text { lower than THW }\end{array}$ \\
\hline
\end{tabular}

Abbreviations: rhTSH, recombinant human thyroid stimulating hormone; THW, thyroid hormone withdrawal; NR, Not reported; Rx, treatments.

Mernagh et al 2006; Pacini et al 2006a; Schroeder et al 2006; Borget et al 2007; Taieb et al 2008).

Other groups have sought to correlate these improvements in morbidity with increased productivity and economic outcomes. In one study, THW resulted in a median of 11 days of missed work (Luster et al 2005), which was equivalent to the cost of administering rhTSH. A recently published study from Europe looked at sick leave as an indirect measure of morbidity. From the 306 patients included, 292 (95\%) completed a questionnaire detailing their treatment, economic and sick leave data. They found there were 194 actively working patients among this group. Those who were treated with rhTSH, when compared to those treated by THW, were less likely to require sick leave $(11 \%$ vs $33 \%, \mathrm{p}=0.001)$. Among those who did require sick leave, the mean duration was shorter (3.1 vs 11.2 days, $\mathrm{p}=0.002$ ) (Borget et al 2007).

Because of the faster clearance of RAI when patients are euthyroid receiving rhTSH and anecdotal reports of shorter hospital admissions for RAI therapy, Borget also evaluated a potential impact on length of hospital stay with 
a case-control study. Thirty-five rhTSH-prepared patients were matched to 64 THW patients on factors affecting RAI clearance. The modeled simulations predicted a length of stay of 2.4 days for patients who received rhTSH preparation compared to 3.5 days for THW preparation ( $p<0.001$ ). This resulted in a savings of $€ 338$, which would defray approximately half the cost of thyrotropin alfa administration (Borget et al 2008).

An economic analysis from a societal perspective evaluated quality of life improvements from avoiding hypothyroidism, increased work productivity, earlier discharge from a radiation safety perspective and theoretical reduction in risk of secondary malignancy. Utilizing a lifetime Markov model expressing benefits in terms of quality adjusted lifeyears (QALY), this analysis found the additional benefits of rhTSH to patients and society at relatively modest net cost (Mernagh et al 2006).

In summary, there is no question that rhTSH-stimulated preparation for diagnostic and therapeutic procedures in thyroid cancer improves patient quality of life, reduces sick time and potentially reduces some direct costs such as hospitalization for radioprotection. Further, quality of life and productivity end-points are particularly important for thyroid cancer patients, since thyroid cancer often strikes young adults, with a median age of presentation of 48 years and about $80 \%$ of patients presenting between the ages of 21 and 65 (SEER 2008).

\section{Summary}

Clearly, development of rhTSH has dramatically changed the initial management and follow-up of patients with well-differentiated thyroid cancer. There is clear evidence that preparation of patients for RAI ablation of thyroid remnants is as efficacious as THW in low risk patients, at least for 2 to 3 years of follow-up. In addition, diagnostic follow-up evaluations with rhTSH-stimulated $\mathrm{Tg}$ are as informative as THW WBS and Tg measurements. Evaluation of this follow-up paradigm has been accompanied by a reconsideration of the role of RAI WBS and a shift to recommendations of rhTSH-stimulated $\mathrm{Tg}$ and neck ultrasonography as the primary modalities of follow-up. The use of rhTSH preparation in these situations and avoidance of hypothyroid symptoms and complications is cost-effective, or even cost-saving (in some macroeconomic models of health care and medical leave coverage). Further, limited studies suggest that whole body and blood radiation exposure from RAI may be lower after rhTSH preparation due to faster renal clearance of iodine, which, theoretically, may reduce long-term complications such as permanent sialoadenitis (Mandel and Mandel 2003) and secondary malignancies (Rubino et al 2003; Sandeep et al 2006; Brown et al 2008).

Unresolved issues remain in regard to the definitive minimal efficacious dose of RAI for remnant ablation, confirmation of the long-term durability of the ablation success with rhTSH, determining optimal paradigms for initial diagnostic WBS and Tg determinations, and determining the required frequency of follow-up stimulated Tg measurements in low risk patients.

\section{Disclosures}

Dr. Schuff is on the Speaker's Bureau for Genzyme Corporation. Dr. Gramza has no conflicts to disclose.

\section{References}

Alzahrani AS, Raef H, Sultan A, et al. 2002. Impact of cervical lymph node dissection on serum TG and the course of disease in TG-positive, radioactive iodine whole body scan-negative recurrent/persistent papillary thyroid cancer. $J$ Endocrinol Invest, 25:526-31.

Barbaro D, Boni G, Meucci G, et al. 2003. Radioiodine treatment with $30 \mathrm{mCi}$ after recombinant human thyrotropin stimulation in thyroid cancer: effectiveness for postsurgical remnants ablation and possible role of iodine content in L-thyroxine in the outcome of ablation. J Clin Endocrinol Metab, 88:4110-5.

Barbaro D, Boni G, Meucci G, et al. 2006. Recombinant human thyroid-stimulating hormone is effective for radioiodine ablation of post-surgical thyroid remnants. Nucl Med Commun, 27:627-32.

Baudin E, Do Cao C, Cailleux AF, et al. 2003. Positive predictive value of serum thyroglobulin levels, measured during the first year of follow-up after thyroid hormone withdrawal, in thyroid cancer patients. $J$ Clin Endocrinol Metab, 88:1107-11.

Berg G, Lindstedt G, Suurkula M, et al. 2002. Radioiodine ablation and therapy in differentiated thyroid cancer under stimulation with recombinant human thyroid-stimulating hormone. J Endocrinol Invest, $25: 44-52$.

Borget I, Corone C, Nocaudie M, et al. 2007. Sick leave for follow-up control in thyroid cancer patients: comparison between stimulation with Thyrogen and thyroid hormone withdrawal. Eur J Endocrinol, 156:531-8.

Borget I, Remy H, Chevalier J, et al. 2008. Length and cost of hospital stay of radioiodine ablation in thyroid cancer patients: comparison between preparation with thyroid hormone withdrawal and thyrogen. Eur J Nucl Med Mol Imaging, 35:1457-63.

Botella-Carretero JI, Galan JM, Caballero C, et al. 2003. Quality of life and psychometric functionality in patients with differentiated thyroid carcinoma. Endocr Relat Cancer, 10:601-10.

Braga M, Ringel MD, Cooper DS, 2001. Sudden enlargement of local recurrent thyroid tumor after recombinant human TSH administration. J Clin Endocrinol Metab, 86:5148-51.

Brown AP, Chen J, Hitchcock YJ, et al. 2008. The risk of second primary malignancies up to three decades after the treatment of differentiated thyroid cancer. J Clin Endocrinol Metab, 93:504-15.

Cailleux AF, Baudin E, Travagli JP, et al. 2000. Is diagnostic iodine-131 scanning useful after total thyroid ablation for differentiated thyroid cancer? J Clin Endocrinol Metab, 85:175-8.

Castagna MG, Brilli L, Pilli T, et al. 2008. Limited value of repeat recombinant human thyrotropin (rhTSH)-stimulated thyroglobulin testing in differentiated thyroid carcinoma patients with previous negative rhTSHstimulated thyroglobulin and undetectable basal serum thyroglobulin levels. J Clin Endocrinol Metab, 93:76-81. 
Cooper DS, Doherty GM, Haugen BR, et al. 2006. Management guidelines for patients with thyroid nodules and differentiated thyroid cancer. Thyroid, 16:109-42.

Crocetti U, Durante C, Attard M, et al. 2008. Predictive value of recombinant human TSH stimulation and neck ultrasonography in differentiated thyroid cancer patients. Thyroid, 18:1049-53.

Dam HQ, Kim SM, Lin HC, et al. 2004. ${ }^{131}$ I therapeutic efficacy is not influenced by stunning after diagnostic whole-body scanning. Radiology, 232:527-33.

de Keizer B, Brans B, Hoekstra A, et al. 2003. Tumour dosimetry and response in patients with metastatic differentiated thyroid cancer using recombinant human thyrotropin before radioiodine therapy. Eur J Nucl Med Mol Imaging, 30:367-73.

de Keizer B, Hoekstra A, Konijnenberg MW, et al. 2004. Bone marrow dosimetry and safety of high ${ }^{131} \mathrm{I}$ activities given after recombinant human thyroid-stimulating hormone to treat metastatic differentiated thyroid cancer. $J$ Nucl Med, 45:1549-54.

Dumont JE, Lamy F, Roger P, et al. 1992. Physiological and pathological regulation of thyroid cell proliferation and differentiation by thyrotropin and other factors. Physiol Rev, 72:667-97.

Edmonds CJ, Hayes S, Kermode JC, et al. 1977. Measurement of serum TSH and thyroid hormones in the management of treatment of thyroid carcinoma with radioiodine. Br J Radiol, 50:799-807.

Elisei R, Corone C, Driedger A, et al. 2007. Follow-up of differentiated thyroid (DTC) cancer patients who underwent radioiodine ablation of postsurgical thyroid remnants after recombinant human thyrotropin (rhTSH) or thyroid hormone withdrawal. Horm Res, 68:33.

Giusti M, Sibilla F, Cappi C, et al. 2005. A case-controlled study on the quality of life in a cohort of patients with history of differentiated thyroid carcinoma. J Endocrinol Invest, 28:599-608.

Goffman T, Ioffe V, Tuttle M, et al. 2003. Near-lethal respiratory failure after recombinant human thyroid-stimulating hormone use in a patient with metastatic thyroid carcinoma. Thyroid, 13:827-30.

Grunwald F, Menzel C, Fimmers R, et al. 1996. Prognostic value of thyroglobulin after thyroidectomy before ablative radioiodine therapy in thyroid cancer. J Nucl Med, 37:1962-4.

Hanscheid H, Lassmann M, Luster M, et al. 2006. Iodine biokinetics and dosimetry in radioiodine therapy of thyroid cancer: procedures and results of a prospective international controlled study of ablation after rhTSH or hormone withdrawal. J Nucl Med, 47:648-54.

Haugen BR, Pacini F, Reiners C, et al. 1999. A comparison of recombinant human thyrotropin and thyroid hormone withdrawal for the detection of thyroid remnant or cancer. $J$ Clin Endocrinol Metab, 84:3877-85.

Hoe FM, Charron M and Moshang T Jr. 2006. Use of the recombinant human TSH stimulated thyroglobulin level and diagnostic whole body scan in children with differentiated thyroid carcinoma. J Pediatr Endocrinol Metab, 19:25-30.

Iervasi A, Iervasi G, Ferdeghini M, et al. 2007. Clinical relevance of highly sensitive $\mathrm{Tg}$ assay in monitoring patients treated for differentiated thyroid cancer. Clin Endocrinol (Oxf), 67:434-41.

Iorcansky S, Herzovich V, Qualey RR, et al. 2005. Serum thyrotropin (TSH) levels after recombinant human TSH injections in children and teenagers with papillary thyroid cancer. J Clin Endocrinol Metab, 90:6553-5.

Jarzab B, Handkiewicz-Junak D, Roskosz J, et al. 2003. Recombinant human TSH-aided radioiodine treatment of advanced differentiated thyroid carcinoma: a single-centre study of 54 patients. Eur J Nucl Med Mol Imaging, 30:1077-86.

Kim TY, Kim WB, Kim ES, et al. 2005. Serum thyroglobulin levels at the time of 131I remnant ablation just after thyroidectomy are useful for early prediction of clinical recurrence in low-risk patients with differentiated thyroid carcinoma. J Clin Endocrinol Metab, 90:1440-5.

Kloos RT and Mazzaferri EL 2005. A single recombinant human thyrotropin-stimulated serum thyroglobulin measurement predicts differentiated thyroid carcinoma metastases three to five years later. JClin Endocrinol Metab, 90:5047-57.
Ladenson PW, Braverman LE, Mazzaferri EL, et al. 1997. Comparison of administration of recombinant human thyrotropin with withdrawal of thyroid hormone for radioactive iodine scanning in patients with thyroid carcinoma. N Engl J Med, 337:888-96.

Leboulleux S, Schroeder PR, Schlumberger M, et al. 2007. The role of PET in follow-up of patients treated for differentiated epithelial thyroid cancers. Nat Clin Pract Endocrinol Metab, 3:112-21.

Lippi F, Capezzone M, Angelini F, et al. 2001. Radioiodine treatment of metastatic differentiated thyroid cancer in patients on L-thyroxine, using recombinant human TSH. Eur J Endocrinol, 144:5-11.

Luster M, Felbinger R, Dietlein M, et al. 2005. Thyroid hormone withdrawal in patients with differentiated thyroid carcinoma: a one hundred thirty-patient pilot survey on consequences of hypothyroidism and a pharmacoeconomic comparison to recombinant thyrotropin administration. Thyroid, $15: 1147-55$

Luster M, Lassmann M, Haenscheid H, et al. 2000. Use of recombinant human thyrotropin before radioiodine therapy in patients with advanced differentiated thyroid carcinoma. J Clin Endocrinol Metab, 85:3640-5.

Luster M, Sherman SI, Skarulis MC, et al. 2003. Comparison of radioiodine biokinetics following the administration of recombinant human thyroid stimulating hormone and after thyroid hormone withdrawal in thyroid carcinoma. Eur J Nucl Med Mol Imaging, 30:1371-7.

Mandac JC, Leboeuf R, Brokhin M, et al. 2008. In properly selected patients, the results of a diagnostic whole-body RAI scan prior to RAI remnant ablation (RRA) seldom alters either the decision to proceed with RRA or the choice of administered activity. Thyroid, 18:S-36.

Mandel SJ and Mandel L 2003. Radioactive iodine and the salivary glands. Thyroid, 13:265-71.

Mariani G, Ferdeghini M, Augeri C, et al. 2000. Clinical experience with recombinant human thyrotrophin (rhTSH) in the management of patients with differentiated thyroid cancer. Cancer Biother Radiopharm, 15:211-7.

Maxon HR, Englaro EE, Thomas SR, et al. 1992. Radioiodine-131 therapy for well-differentiated thyroid cancer-a quantitative radiation dosimetric approach: outcome and validation in 85 patients. $J$ Nucl Med, 33:1132-6.

Mazzaferri EL, Robbins RJ, Spencer CA, et al. 2003. A consensus report of the role of serum thyroglobulin as a monitoring method for low-risk patients with papillary thyroid carcinoma. J Clin Endocrinol Metab, 88:1433-41.

Meier CA, Braverman LE, Ebner SA, et al. 1994. Diagnostic use of recombinant human thyrotropin in patients with thyroid carcinoma (phase I/II study). J Clin Endocrinol Metab, 78:188-96.

Menzel C, Kranert WT, Döbert N, et al. 2003. rhTSH stimulation before radioiodine therapy in thyroid cancer reduces the effective half-life of (131)I. J Nucl Med,44:1065-8.

Mernagh P, Campbell S, Dietlein M, et al. 2006. Cost-effectiveness of using recombinant human TSH prior to radioiodine ablation for thyroid cancer, compared with treating patients in a hypothyroid state: the German perspective. Eur J Endocrinol, 155:405-14.

Montesano T, Durante C, Attard M, et al. 2007. Age influences TSH serum levels after withdrawal of 1-thyroxine or rhTSH stimulation in patients affected by differentiated thyroid cancer. Biomed Pharmacother, 61:468-71.

Niederkohr RD and McDougall IR. 2007. Reproducibility of whole-body 131I scan and serum thyrotropin and stimulated thyroglobulin values in patients studied twice after injection of recombinant human thyrotropin. Eur J Nucl Med Mol Imaging, 34:363-7.

Pacini F, Capezzone M, Elisei R, et al. 2002. Diagnostic 131-iodine whole-body scan may be avoided in thyroid cancer patients who have undetectable stimulated serum $\mathrm{Tg}$ levels after initial treatment. $J$ Clin Endocrinol Metab, 87:1499-501.

Pacini F, Cetani F, Miccoli P, et al. 1994. Outcome of 309 patients with metastatic differentiated thyroid carcinoma treated with radioiodine. World J Surg, 18:600-4.

Pacini F, Ladenson PW, Schlumberger M, et al. 2006a. Radioiodine ablation of thyroid remnants after preparation with recombinant human thyrotropin in differentiated thyroid carcinoma: results of an international, randomized, controlled study. J Clin Endocrinol Metab, 91:926-32. 
Pacini F, Molinaro E, Castagna MG, et al. 2002. Ablation of thyroid residues with $30 \mathrm{mCi}(131) \mathrm{I}$ : a comparison in thyroid cancer patients prepared with recombinant human TSH or thyroid hormone withdrawal. $J$ Clin Endocrinol Metab, 87:4063-8.

Pacini F, Molinaro E, Castagna MG, et al. 2003. Recombinant human thyrotropin-stimulated serum thyroglobulin combined with neck ultrasonography has the highest sensitivity in monitoring differentiated thyroid carcinoma. J Clin Endocrinol Metab, 88:3668-73.

Pacini F, Schlumberger M, Dralle H, et al. 2006b. European consensus for the management of patients with differentiated thyroid carcinoma of the follicular epithelium. Eur J Endocrinol, 154:787-803.

Park SG, Reynolds JC, Brucker-Davis F, et al. 1996. Iodine kinetics during I-131 scanning in patients with thyroid cancer: comparison of studies with recombinant human TSH (rhTSH) vs hypothyroidism. J Nucl Med, 37:15.

Pellegriti G, Scollo C, Giuffrida D, et al. 2001. Usefulness of recombinant human thyrotropin in the radiometabolic treatment of selected patients with thyroid cancer. Thyroid, 11:1025-30.

Pilli T, Brianzoni E, Capoccetti F, et al. 2007. A comparison of $1850(50 \mathrm{mCi})$ and $3700 \mathrm{MBq}(100 \mathrm{mCi}) 131$-iodine administered doses for recombinant thyrotropin-stimulated postoperative thyroid remnant ablation in differentiated thyroid cancer. J Clin Endocrinol Metab, 92:3542-6.

Potzi C, Moameni A, Karanikas G, et al. 2006. Comparison of iodine uptake in tumour and nontumour tissue under thyroid hormone deprivation and with recombinant human thyrotropin in thyroid cancer patients. Clin Endocrinol (Oxf), 65:519-23.

Robbins RJ, Driedger A, Magner J. 2006a. Recombinant human thyrotropinassisted radioiodine therapy for patients with metastatic thyroid cancer who could not elevate endogenous thyrotropin or be withdrawn from thyroxine. Thyroid, 16:1121-30.

Robbins RJ, Larson SM, Pentlow KS, et al. 2002a. Effectiveness of I-131 in destroying metastatic thyroid cancer lesions. Thyroid, 12:199.

Robbins RJ, Larson SM, Sinha N, et al. 2002b. A retrospective review of the effectiveness of recombinant human TSH as a preparation for radioiodine thyroid remnant ablation. $J$ Nucl Med, 43:1482-8.

Robbins RJ, Tuttle RM, Sonenberg M, et al. 2001. Radioiodine ablation of thyroid remnants after preparation with recombinant human thyrotropin. Thyroid, 11:865-9.

Robbins RJ, Voelker E, Wang W, et al. 2000. Compassionate use of recombinant human thyrotropin to facilitate radioiodine therapy: case report and review of literature. Endocr Pract, 6:460-4.

Robbins RJ, Wan Q, Grewal RK, et al. 2006b. Real-time prognosis for metastatic thyroid carcinoma based on 2-[18F]fluoro-2-deoxy-Dglucose-positron emission tomography scanning. J Clin Endocrinol Metab, 91:498-505.

Rosario PW, Borges MA, Purisch S. 2008. Preparation with recombinant human thyroid-stimulating hormone for thyroid remnant ablation with 131I is associated with lowered radiotoxicity. $J$ Nucl Med, 49:1776-82.

Rosario PW, Maia FF, Cardoso LD, et al. 2004. Correlation between cervical uptake and results of postsurgical radioiodine ablation in patients with thyroid carcinoma. Clin Nucl Med, 29:358-61.

Rubino C, de Vathaire F, Dottorini ME, et al. 2003. Second primary malignancies in thyroid cancer patients. Br J Cancer, 89:1638-44.

Rudavsky AZ and Freeman LM 1997. Treatment of scan-negative, thyroglobulin-positive metastatic thyroid cancer using radioiodine 131I and recombinant human thyroid stimulating hormone. $J$ Clin Endocrinol Metab, 82:11-4.

Sandeep TC, Strachan MW, Reynolds RM, et al. 2006. Second primary cancers in thyroid cancer patients: a multinational record linkage study. J Clin Endocrinol Metab, 91:1819-25.

Schlesinger T, Flower MA and McCready VR. 1989. Radiation dose assessments in radioiodine (131I) therapy. 1. The necessity for in vivo quantitation and dosimetry in the treatment of carcinoma of the thyroid. Radiother Oncol, 14:35-41.
Schlumberger M, Berg G, Cohen O, et al. 2004. Follow-up of low-risk patients with differentiated thyroid carcinoma: a European perspective. Eur J Endocrinol, 150:105-12.

Schroeder PR, Haugen BR, Pacini F, et al. 2006. A comparison of short-term changes in health-related quality of life in thyroid carcinoma patients undergoing diagnostic evaluation with recombinant human thyrotropin compared with thyroid hormone withdrawal. J Clin Endocrinol Metab, 91:878-84.

SEER. 2008. SEER Stat Fact Sheets - Thyroid. SEER Cancer Statistics Review, 1975-2005. Accessed 26 November 2008. URL: http://seer. cancer.gov/csr/1975_2005/.

Smallridge RC, Meek SE, Morgan MA, et al. 2007. Monitoring thyroglobulin in a sensitive immunoassay has comparable sensitivity to recombinant human TSH-stimulated thyroglobulin in follow-up of thyroid cancer patients. J Clin Endocrinol Metab, 92:82-7.

Szkudlinski MW, Thotakura NR, Bucci I, et al. 1993. Purification and characterization of recombinant human thyrotropin (TSH) isoforms produced by Chinese hamster ovary cells: the role of sialylation and sulfation in TSH bioactivity. Endocrinology, 133:1490-503.

Taieb D, Lussato D, Guedj E, et al. 2006. Early sequential changes in serum thyroglobulin after radioiodine ablation for thyroid cancer: possible clinical implications for recombinant human thyrotropin-aided therapy. Thyroid, 16:177-9.

Taieb D, Lussato D, Mundler O. 2004. Subcutaneous administration of recombinant human thyrotropin as an alternative to thyroid hormone withdrawal in patients with anticoagulated thyroid cancer: preliminary results. Thyroid, 14:463-4.

Taieb D, Sebag F, Cherenko M, et al. 2008. Quality of life changes and clinical outcomes in thyroid cancer patients undergoing radioiodine remnant ablation with recombinant human thyrotropin: a randomized controlled study. Clin Endocrinol ( $O x f$ ), in press.

Torlontano M, Crocetti U, D'Aloiso L, et al. 2003. Serum thyroglobulin and 131I whole body scan after recombinant human TSH stimulation in the follow-up of low-risk patients with differentiated thyroid cancer. Eur J Endocrinol, 148:19-24.

Toubeau M, Touzery C, Arveux P, et al. 2004. Predictive value for disease progression of serum thyroglobulin levels measured in the postoperative period and after (131)I ablation therapy in patients with differentiated thyroid cancer. $J$ Nucl Med, 45:988-94.

Tuttle RM, Brokhin M, Omry G, et al. 2008. Recombinant human $\mathrm{TSH}$-assisted radioactive iodine remnant ablation achieves short-term clinical recurrence rates similar to those of traditional thyroid hormone withdrawal. J Nucl Med, 49:764-70.

Vaiano A, Claudio Traino A, Boni G, et al. 2007. Comparison between remnant and red-marrow absorbed dose in thyroid cancer patients submitted to 131I ablative therapy after rh-TSH stimulation versus hypothyroidism induced by L-thyroxine withdrawal. Nucl Med Commun, 28:215-23.

Vargas GE, Uy H, Bazan C, et al. 1999. Hemiplegia after thyrotropin alfa in a hypothyroid patient with thyroid carcinoma metastatic to the brain. $J$ Clin Endocrinol Metab, 84:3867-71.

Vitale G, Lupoli GA, Ciccarelli A, et al. 2003. Influence of body surface area on serum peak thyrotropin (TSH) levels after recombinant human TSH administration. J Clin Endocrinol Metab, 88:1319-22.

Wang W, Larson SM, Fazzari M, et al. 2000. Prognostic value of [18F]fluorodeoxyglucose positron emission tomographic scanning in patients with thyroid cancer. J Clin Endocrinol Metab, 85:1107-13.

Zanotti-Fregonara P, Duron F, Keller I, et al. 2007. Stimulation test in the follow-up of thyroid cancer: plasma rhTSH levels are dependent on body weight, not endogenously stimulated TSH values. $\mathrm{Nucl} \mathrm{Med}$ Commun, 28:257-9. 
